\title{
Changing body habitus among healthy older men: The NAS Boston VA study of weight stability in healthy male volunteers aged 40-80 years
}

\author{
Joel Grinker, David Rush and Pantel Vokonas
}

Boston VA; USDA-Tufts University, 711 Washington Street, Boston MA 02111 and University of Michigan, Ann Arbor, MI 48109, USA

\section{Introduction}

Fluctuations in weight/fatness are compared in a longitudinal study of male participants aged 40-80 years from the Normative Aging Study (NAS) at the Veterans Administration Outpatient Clinic in Boston. The incidence and prevalence of repetitive weight changes and factors associated with stability in body habitus are examined. The contributions of secular trends in weight/fatness, fat distribution patterns, family weight history, dieting efforts, and nutrient intakes to weight stability are discussed.

\section{Contributions of aging to weight stability}

Cross-sectional studies have documented the effects of age, gender, race and secular influences on changing body habitus $[1,31,33,41]$. The US population has reportedly gained weight over the last two decades and the prevalence of obesity has increased even in childhood and adolescence [15,17,37]. Overweight among adults of varying ages has increased within the last 10 years despite widespread health concerns and dieting [13,38]. Recent statistics suggest that in 1986, 28.4\% of US adults 25 to 74 years of age were $20 \%$ or more overweight judged by body mass index $(B M I) \geq 27.8$ for men and 27.3 for women [33].

Cross-sectional studies in England, Canada, US and Holland report that in both men and women, relative weight increases during adulthood, is maintained in middle age and decreases in old age $[3,20,22,28,29,32,33,35,39]$. These associations between age and weight might be partly a result of differential mortality in the lean or obese or to both cohort and age effects which are possible in cross-sectional studies. However, data from prospective studies support these general findings.

Longitudinal studies suggest age related trends in relative weight [14,19,21]. Existing prospective studies suggest relative consistency in body weight patterns over time. Changes in weight, BMI, and skinfold thickness (triceps and subscapu- 
lar) were studied over 4-7 year intervals in 17,000 Finnish adults in a recent health survey [34]. Average weight and BMI increased with age in men and women below age 50 at entry, changed little in men aged 50-70 (women 50-60) and declined at later ages. Both moderate overweight (BMI $27.0-29.9 \mathrm{~kg} / \mathrm{m}^{2}$ ) and severe overweight (BMI $\geq 30 \mathrm{~kg} / \mathrm{m}^{2}$ ) increased in successive age cohorts of men and women until age 70 years. Approximately $24.7 \%$ of all Finnish men and $33.7 \%$ of all women were considered overweight and $8.3 \%$ of men and $17.4 \%$ of women were estimated to be severely overweight.

Small changes in individual weights were reported; two-thirds of the participants maintained their weight within $5 \mathrm{~kg}$ of their original weight classification (lean, normal, moderately or severely overweight). A weight gain of $10 \mathrm{~kg}$ or more occurred in $9 \%$ of the males, $4 \%$ of the females and a $10 \mathrm{~kg}$ weight loss in only $2 \%$ of the males and $4 \%$ of the females. Both weight loss and weight gain occurred among overweight subjects. Weight loss was associated with old age and higher initial BMI whereas weight gain was most common in young adults even among those with high initial BMI. Among 40-69 year old men there were negligible changes with $15 \%$ losing or gaining $5 \mathrm{~kg}$. BMI increased until age 50 and decreased thereafter.

\section{Weight cycling}

Cycles of weight loss and regain have been hypothesized to alter metabolism permanently. This 'weight cycling' effect has variously been defined as an increased difficulty in losing weight requiring greater caloric restriction or longer periods of time to achieve previous levels, more rapid or greater weight regain or a seemingly permanent decrease in energy needs [11]. Postulated mechanisms include lasting declines in resting metabolic rate, increased efficiency in fat utilization and storage or differences in lipoprotein lipase activity and fat cell morphology $[6,7,11]$.

The extent of repeated cycles of dieting and/or recidivism in the normal or nonclinic population is unknown. At present, the results of studies of human dieters are inconsistent and fail to support hypotheses of repeated weight loss and gain producing increased efficiency in fat utilization and storage [ 7 vs 40 ]. Currently, results are viewed as both inconclusive and circumstantial and any apparent mechanism controversial.

Recently, studies have focused on the deleterious consequences of weight changes reporting greater morbidity and mortality solely as a consequence of weight fluctuations [18]. Recent reports from the MRFIT, Goteborg and Framingham populations suggest an association between weight cycling (individual variations in body weight) and CHD and mortality independent of BMI or age $[2,25,26]$. It has recently been suggested that stability in body habitus may be related to a lower risk for cardiovascular disease (CVD) [16]. Data were based on self-reported weights (at ages 20 to 40 ) by $45-56$ year old men in the Western Electric study. The minority of participants reporting one of three weight patterns (no change, 
gain only, or gain and loss) were compared with all other participants. A proportional-hazards regression analysis was used to examine the relative risk of death among the groups after adjustment for confounding variables. Weight fluctuations among younger subjects appeared to be related to increased mortality 25 years later. Recent data from the Baltimore Longitudinal Aging Study [25] suggest that fluctuations in body weight are related to greater decreases in glucose tolerance and greater increases in the ratio of subscapular to triceps skinfolds but not with waist-hip ratio, serum cholesterol or triglyceride levels or subsequent CVD. Weight fluctuations might influence possible cardiovascular risk via redistribution of fat patterns or impairments in glucose tolerance.

\section{Pattern of fat distribution and age}

A major factor in the correlation between excess adiposity and morbidity/mortality may be the anatomical distribution of adipose tissue. At equivalent fatness levels, individuals with predominately central (android) patterns of fat distribution will experience higher rates of atherosclerotic heart disease, stroke, hypertension, hyperlipidemia and diabetes than will similarly fat individuals with predominately peripheral (gynoid) patterns of fat distribution [12,23,24]. Other studies report that age produces progressive trends toward increasing upper to central body fat deposition [36]. Great variability among individuals in the redistribution of fat with increasing age has also been documented [30]. Results from computer based tomography studies of intra-abdominal fat deposition show greater accumulation in older subjects [10].

\section{The normative aging study (NAS)}

Most studies have been limited by reliance on self reported weights or BMI, small sample sizes, low variability in age ranges or reduced levels of initial body habitus. The added contributions of age, sequential fluctuations, initial body habitus or pattern of fat distribution are usually ignored or eliminated. Data on 'natural' weight shifts or deliberate dieting are typically unavailable. The extent and timing of weight changes or stability in body habitus in relation to family background or pattern of fat distribution are unknown. It is unclear whether the risks of other chronic diseases are also related to weight fluctuations or whether the addition of age, gender and obesity greatly increase the prevalence and degree of weight fluctuations or the long term risks.

Prospective studies provide the ideal vehicle to document the degree of stability in weight and fatness patterns over the life span of older Americans. Factors leading to success or failure in weight loss and maintenance such as intentionality, repeated efforts, diet or exercise, degree and duration of overweight, age at onset of obesity, familial background and fat distribution patterns can be identified. Dieting efforts are likely to show both secular and cohort effects, varying as a function of 
degree of overweight, age and/or morbidity. Thus, it is desirable to obtain data from a longitudinal sample, of initially healthy individuals who can be classified at the outset on a continuum of body habitus and in whom fat distribution patterns can be ascertained. An ideal opportunity to document the existence of weight fluctuations among individuals of varying body habitus, factors involved in the stability and persistence of obesity, and the consequences of both excess weight and changes in weight exists in the ongoing prospective study of healthy men aged 40-80 enrolled in the Normative Aging Study (NAS) [5].

Use of the NAS data base allows precise measurement of long term incidence and prevalence of weight fluctuations among various age cohorts. Evidence for a 'weight cycling effect' i.e., an increased rate of regain, decreased rate of subsequent weight loss or increased amount of weight regain can be examined. Data are also available to determine the relationships among weight fluctuations, patterns of fat distribution and health risks. Empirical data include measured height and weights and anthropometric data from the time of enrollment (i.e., > 15 years). Thus, fat patterning as well as subject reliability or memory of weight history status can be checked.

Subjects are selected from the ongoing VA Normative Aging Study [5]. Boston men ( $n=2,280$ ) aged 21-81 years (mean age 42 years) were enrolled during 1961-1970. Clinical examinations have continued at 3-5 year intervals depending on age ( $<$ or $>52$ ). Data on the approximately 1,800 remaining men include regular clinical and anthropometric measurements (weight, height, skinfolds, circumferences, etc.) and recent data include activity questionnaires, food frequencies, various biochemical indices, tobacco and alcohol use, and reported heights and weights for spouses at enrollment. Only initially healthy volunteers were included e.g., those with hypertension, diabetes, CVD etc., were excluded. Body habitus however, was not a criterion for exclusion.

These data allow determination of the existence of repeated cycles of weight loss/gain in community samples of older men, the relative stability in weight patterns among individuals of differing ages with differing patterns of fat distribution and associated CVD risk factors. Answers to the following questions can be obtained: How stable is body habitus in adult white males aged 40-80? Are certain patterns of fat distribution (centripetal or abdominal (internal) depots) more likely to lead to instability in body habitus or be more closely linked with morbidity/ mortality and family background? Are repeated cycles of weight shifts related to either increased morbidity or permanent alterations in metabolism?

\section{References}

1. Abraham S, Carroll MD, Najjar MF and Robinson F (1983) Obese and overweight adults in the United States. Vital and Health Statistics USDHHS Publ. No. (PHS) 83-1680, PHS NCHS Series 11, No. 230.

2. Anderson KM, Castelli WP and Stokes J (1989) Repeated measures of body mass index and mortality: The Framingham Study. Abst. Soc. Epidem. Res. 
3. Baecke JAH, Burema J, Frijters JER, Hautvast JGAJ and van der Wicl-Wetzels WAM (1983) Obcsity in young Dutch adults: I, Socio-demographic variables and body mass index. Int. J. Obesity. 7: $1-12$.

4. Baumgartner RN, Roche AF, Chumlea WC, Siervogel RM, Glueck CJ (1987) Fatness and fat patterns: Associations with plasma lipids and blood pressures in adults 18 to 57 years of age. Am. J. Epidemiol. 126: 614-628.

5. Bell B, Rose CL and Damon A (1972) The Veterans Administration longitudinal study of healthy aging. Gerontologist 6: 179-184.

6. Bjorntorp PM and Yang MU (1982) Refeeding after fasting in the rat: Effects on body composition and food efficiency. Am. J. Clin. Nutr. 36: 444-449.

7. Blackbum GL, Wilson GT, Kanders BS, Stein LJ, Lavin PT. Adler J and Brownell KD (1989) Weight cycling: The experience of human dieters. Am. J. Clin. Nutr. 49: 1105-1109.

8. Borkan GA, Hults DE and Glynn RJ (1983) Role of longitudinal change and secular trend in age differences in male body dimensions. Hum. Biol. 55: 629-641.

9. Borkan GA, Sparrow D, Wisniewski C and Vokonas PS (1986) Body weight and coronary disease risk: Patterns of risk factor change associated with longterm weight change. Am. J. Epid. 124: 410-419.

10. Borkan GA, Hults DE, Gerzof SG, Robbins AH and Silbert CK (1983) Age changes in body composition revealed by computed tomography. J. Gerontol. 38: 673-677.

11. Brownell KD, Greenwood MRC, Stellar E and Shrager EE (1986) The effects of repeated cycles of weight loss and regain in rats. Physiol. Behav. 38: 459-464.

12. Ducimetiere P, Richard J, Cambien F, Avous P and Jacqueson A (1985) Relationship between adiposity measurements and the incidence of coronary heart disease in a middle-aged male population: The Paris Prospective Study I. Am. J. Nutr. 4: 31-38.

13. Fisher KD and Bennett (1985) Report of the scientific community's views on progress in attaining the PHS objectives for improved nutrition in 1990. Bethesda MD. Life Science Research Office, FASEB.

14. Friedlaender JS, Costa PT, Bosse R, Ellis E, Rhoads JG and Stoudt HW (1977) Longitudinal physique changes among healthy white veterans at Boston. Hum. Biol. 49: 541-558.

15. Gortmaker S and Dietz WD (1987) (details available from author.)

16. Hamm P, Shekelle RB and Stamler J (1989) Large fluctuations in body weight during young adulthood and twenty-five year risk of coronary death in men. Am. J. Epidemiol. 129: 312318.

17. Harlan WR, Landis JR, Flegal KM, Davis CS and Miller ME (1988) Secular trends in body mass in the United States. Am. J. Epidemiol. 128: 1065-1074.

18. Hoffmans MDAF and Kromhout D (1989) Changes in body mass index in relation to myocardial infarction (the Zutphen-study). Abst. Int. J. Obesity 13: 25.

19. Hsu PH, Mattewson FAL and Rabkin SW (1977) Blood pressure and body mass index patterns: A longitudinal study. J. Chron. Dis. 30: 93-113.

20. Jeffrey RW, Folsam AR, Luepker RV et al. (1984) Prevalence of overweight and weight loss behavior in a metropolitan adult population: The Minnesola heart-survey experience. Am. J. Public Health 74(4): 349-352.

21. Kannel WB, Gordon T and Castelli WP (1979) Obesity, lipids, and glucose intolerance. The Framingham Study. Am. J. Clin. Nutr. 32: 1238-1245.

22. Khosla $T$ and Lowe CR (1968) Height and weight of British men. Lancet 1: 742-745.

23. Lapidus L, Bengtsson C, Larsson B, Pennert K, Rybo E and Sjostrom L (1984) Distribution of adipose tissue and risk of cardiovascular disease and death: A 12-year follow-up of participants in the population study of women in Gothenburg, Sweden. Br. Med. J. 289: 1257-1261.

24. Larsson B, Svardsudd K, Welin L, Wilhelmsen L, Bjorntorp P and Tibblin G (1984) Abdominal adipose tissue distribution, obesity and risk of cardiovascular disease and death. Br. Med. J. 288: 1401-1404.

25. Lissner L, Andres R, Muller DC and Shimokata H (1989) Body weight fluctuation in men: Metabolic rate, health and longevity. Abst. NASSO.

26. Lissner L, Collins G, Blair SN and Brownell KD (1988) Weight fluctuation and mortality in the MRFIT population. Abst. Soc. Epidemiol. Research. 
27. Lissner L, Odell P, D'Agostino R, Stokes J, Kreger B, Belanger A and Brownell K (1988) Health implications of weight cycling in the Framingham population. Abst. Soc. Epidemiol. Res.

28. Millar WJ and Stephens TS (1987) The prevalence of overweight and obesity in Britain, Canada, and United States. Am. J. Public Health 77: 38-41.

29. Monotoye HJ, Epstein FH and Kjelsberg MO (1965) The measurement of body fatness. A study in a total community. Am. J. Clin. Nutr. 16: 417-427.

30. Mueller WH. (1982) The changes with age of the anatomical distribution of fat. Soc. Sci. Med. 16: 191-196.

31. National Center for Health Statistics (1966) Weight by height and age of aduits, United States, 1960-1962. (Vital and Health Statistics Series 1, No. 14) HEW, Washington, DC, USA.

32. National Center for Health Statistics (1980) Health practice among adults: US, 1977. Advance data from vital and health statistics. (PHS, No 64) HEW, Washington, DC, USA.

33. National Center for Health Statistics. Health, United States, 1986. DHHS Publ. (PHS) 87-1232. Public Health Service. Washington, DC, US Gov. Printing Office. Dec., 1986.

34. Rissanen A, Heliovaara $M$ and Aromaa A (1988) Overweight and anthropometric changes in adulthood: A prospective study of 17,000 Finns. Int. J. Obesity, 12: 391-401.

35. Rosenbaum S, Skinner RK, Knight IB and Garrow JS (1985) A survey of heights and weights of adults in Great Britain. Ann. Hum. Biol. 12: 115-127.

36. Shimokata H, Tobin JD, Muller DC, Elahi D, Coon PJ and Andres R (1989) Studies in the distribution of body fat: Effects of age, sex and obesity. J. Gerontol. 44: 66-73.

37. Simopoulos AP (1987) Characteristics of obesity: An overview. In: Wurtman RJ and Wurtman JJ (eds.) Human Obesity. Ann. NY Acad. Sci. USA 499: 4-13.

38. Stephenson MG (1987) J. Nutr. Educ. 19: 155.

39. Stewart AL and Brook RH (1983) Effects of being overweight. Am J. Public Health 73: 171-178.

40. Van Dale D and Saris WHM (1989) Repetitive weight loss and weight regain: Effects on weight reduction, resting metabolic rate, and lipolytic activity before and after exercise and/or diet treatment. Am. J. Clin. Nutr. 49: 409-416.

41. Wong FL and Trowbridge FL (1984) Nutrition surveys and surveillance: Their application to clinical practice. Clin. Nutr. 3: 94-99. 